\title{
Frontières
}

\section{POTVIN, Magella, Épreuve, souffrance et maladies, Chicoutimi (Québec), Les Éditions CPS, 2001, 308 p.}

\section{Michel Clément}

Volume 15, numéro 1, automne 2002

URI : https://id.erudit.org/iderudit/1073916ar

DOI : https://doi.org/10.7202/1073916ar

Aller au sommaire du numéro

\section{Éditeur(s)}

Université du Québec à Montréal

\section{ISSN}

1180-3479 (imprimé)

1916-0976 (numérique)

Découvrir la revue

Citer ce compte rendu

Clément, M. (2002). Compte rendu de [POTVIN, Magella, Épreuve, souffrance et maladies, Chicoutimi (Québec), Les Éditions CPS, 2001, 308 p.] Frontières, 15(1), 80-80. https://doi.org/10.7202/1073916ar d'utilisation que vous pouvez consulter en ligne.

https://apropos.erudit.org/fr/usagers/politique-dutilisation/ 


\section{POTVIN, Magella. \\ Épreuve, souffrance et maladies}

Chicoutimi (Québec),

Les Éditions CPS, 2001, 308 p.

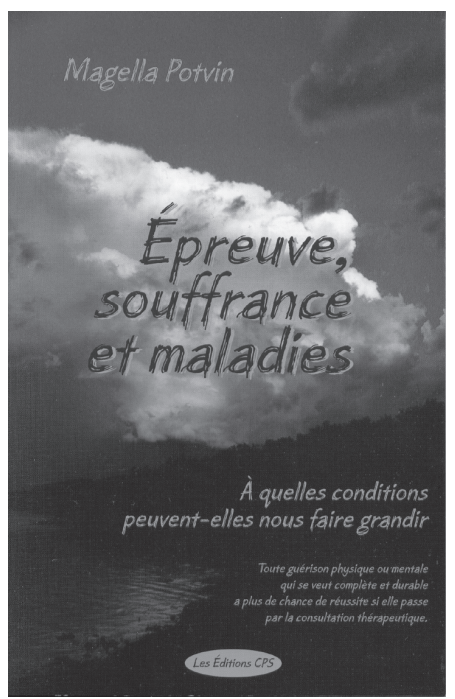

II ne faut pas s'attendre en lisant ce livre à une étude qui s'adresse essentiellement aux spécialistes, d'ailleurs l'auteur insiste sur le fait qu'il écrit pour un public plus large: "Ce livre s'adresse prioritairement à ceux qui espèrent une guérison plus durable, à ceux en rémission qui vivent l'angoisse de la récidive, à ceux qui croient à une prévention plus efficace, à ceux qui ont le courage d'accompagner un proche, un patient, un client, un bénéficiaire ou un usager dans l'expérience de sa maladie ainsi qu'à ceux qui s'intéressent au cancer et à la maladie tant physique que mentale» (p. 10). Ainsi, il sera difficile de mettre de la distance à l'égard de cette approche thérapeutique issue du psychanalyste suisse Ludwig Binswanger (1881-1966), que l'auteur ne mentionne cependant pas dans sa bibliographie, et qui fut l'un de ceux qui jetèrent les bases de ce que I'on nomme la Dasein therapie, issue du travail du philosophe allemand, Martin Heidegger (1889-1976). L'auteur fait état dans son introduction certaines influences dont celles du psychiatre zurichois, Médard Boss (1903-1990) et de deux théologiens soit Edward Schillebeeckx (1914-) et Leonardo Boff (1938-) qui l'aidèrent à développer certains aspects de son travail.
En fait, Potvin nommera son approche "psychoimmunologie", ce qui suppose donc une thérapie appropriée qui mettra toujours en cause et aussi à contribution les manifestations somatiques de sa maladie, les nœuds névrotiques qui en sont la base et l'aspect spirituel de ces questions.

L'approche de l'auteur est à la fois théorique et pratique: chaque chapitre est suivi de tableaux de synthèse très précis et de nombreux cas cliniques afin d'illustrer son propos; on $y$ retrouvera aussi quelques tableaux, des "définitions contextuelles ", des notes et une bibliographie des ouvrages consultés.

Magella Potvin relève, en conclusion, que le modèle qu'il propose ne pourrait se prêter à une étude épistémologique qui en contrôlerait à la fois les bases théoriques et les effets thérapeutiques: "Une autre raison pour laquelle je ne me sens aucunement porté à justifier scientifiquement le modèle que je propose est que je ne guéris personne. L'auteur de la guérison est toujours l'analysé lui-même. "Ta foi t'a sauvé" disait le Nazaréen » (p. 248). II n'en reste pas moins que toutes les thérapies même les plus articulées sont soumises, et cela sans exception, à la loi du transfert/contre-transfert et à bien d'autres; à partir de celles-ci, l'analyse d'une "guérison " prend des chemins inattendus, mais il est tout de même essentiel de comprendre l'ensemble du processus théorique et thérapeutique de toute intervention qui tient compte du psychisme et de la spiritualité, afin d'éviter les dérives, toujours très graves, qui pourraient faire de l'analysé un être "en capture ", dépossédé de sa liberté, déjà fortement mise en cause par la maladie et la souffrance. Il est toujours important de mettre à nu la circularité de certaines thérapeutiques qui ne semblent vouloir se vérifier que par elles-mêmes; l'épreuve des faits et de la théorie qui les interprète est à plusieurs égards irremplaçable.

Michel Clément 